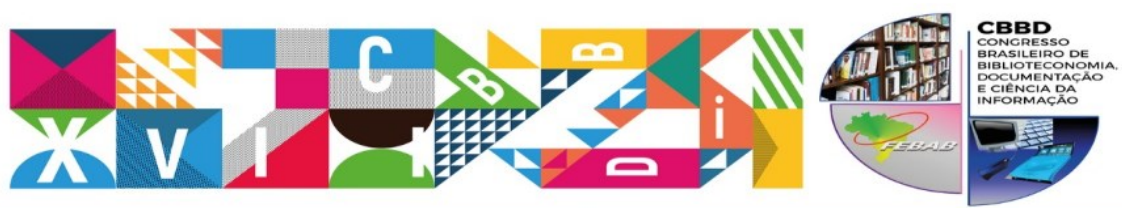

XXVII CONGRESSO BRASILEIRO DE BIBLIOTECONOMIA,

DOCUMENTAÇÃO E CIÊNCIA DA INFORMAÇÃO

TEMA CENTRAL: Objetivos para o Desenvolvimento Sustentável das Naçōes Unidas:
como as bibliotecas podem contribuir com a implementaçăo da Agenda 2030

Eixo 2 - $3^{\circ}$ Fórum de Biblioteconomia Escolar

\title{
MEDIAÇÃO DA INFORMAÇÃO EM BIBLIOTECA ESCOLAR: um estudo realizado na biblioteca Madre Paula do Colégio Santa Teresa de Jesus
}

\author{
Antonia Janiele Moreira da \\ Silva \\ Bibliotecária do Colégio Santa Teresa \\ de Jesus. Mestranda em \\ Biblioteconomia na Universidade \\ Federal do Cariri. \\ E-mail: janielemoreira14@gmail.com
}

\section{Francisca Eugenia Gomes \\ Duarte}

Professora do Curso de Letras da Universidade Regional do Cariri. Mestranda em Biblioteconomia pela Universidade Federal do Cariri.

E-mail: eugenia.duarte@urca.br

\section{Jonathas Luiz Carvalho Silva}

Professor Adjunto do curso de Graduação em Biblioteconomia do Mestrado Profissional em

Biblioteconomia da Universidade Federal do Cariri. Doutor em Ciência da Informação pela Universidade Federal da Bahia.

E-mail:

jonathascarvalho@yahoo.com.br

\section{RESUMO}

Apresenta como objetivo investigar as atividades de mediação da informação implícita e explícita realizadas na biblioteca Madre Paula do Colégio Santa Teresa de Jesus. 0 presente estudo aborda percepções teóricas sobre mediação da informação, na visão de Almeida Júnior (2009), com ênfase na mediação implícita e explícita. Silva (2010), mediação custodial e pós-custodial e Silva (2015), mediação técnica, pedagógica e institucional. A metodologia da pesquisa é de cunho bibliográfico, assim como de natureza qualitativa e quantitativa. Conclui-se que ser um bibliotecário mediador da informação requer deste profissional uma postura inovadora, qualificada e atualizada. Embora o conceito de mediação ainda esteja se solidificando na área da Biblioteconomia, é ação constante no ambiente biblioteca. É essencial que os usuários tenham um espaço dinâmico, que propicie a apropriação da informação.

Palavras-Chave: Mediação da Informação. Biblioteca Escolar. Práticas Mediacionais.

\section{INFORMATION MEDIATION IN SCHOOL LIBRARIES: a study carried out in the Mother Paula library of the Santa Tereza de Jesus school}

\section{ABSTRACT}

Its objective is to investigate the implicit and explicit information mediation activities realized in the Mother Paula library at Santa Teresa de Jesus School. It addresses to theoretical perceptions about the information mediation according to Almeida Júnior (2009), emphasizing the implicit and explicit mediation through Silva (2010), custody and post-custody mediation by the vision of Silva (2015). It's a bibliographical research of a qualitative and quantitative 


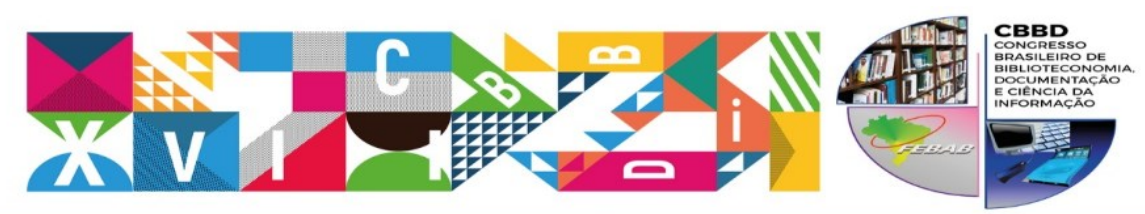

XXVII CONGRESSO BRASILEIRO DE BIBLIOTECONOMIA,

DOCUMENTAÇÃO E CIÊNCIA DA INFORMAÇÃO

TEMA CENTRAL: Objetivos para o Desenvolvimento Sustentável das Naçōes Unidas:
como as bibliotecas podem contribuir com a implementaçăo da Agenda 2030

nature. It concluded that being an information mediator librarian requires professional attitude and an innovative qualified and updated posture. Although the concept of mediation is still solidifying in the Librarianship field, it constantly happens in the library environment and it is essential that the users have a dynamic space that allows an appropriation of the information

Keywords: Mediation of Information. Library School. Mediation Practices.

\section{INTRODUÇÃO}

A mediação da informação está tendo cada vez mais relevância na área da Biblioteconomia contemporânea, assim, como na Ciência da Informação. Sendo estudada em diversos âmbitos, no ambiente da biblioteca é considerada fator nato para o desenvolvimento das atividades.

Vale ressaltar a responsabilidade do bibliotecário, enquanto mediador da informação. Visto que esta é insumo crucial nos mais diversos setores. No ambiente informacional, em específico a biblioteca, é elemento fundamental. Sabe-se também da importância da informação para o desenvolvimento do indivíduo na sociedade. Para Barreto (2002, p. 49) a informação "[...] um instrumento modificador da consciência do indivíduo e de seu grupo social, pois sintoniza o homem com a memória de seu passado e com as perspectivas de seu futuro."

Nesta acepção mediar informação requer um olhar muito cauteloso por parte do bibliotecário, assim, como exige um perfil proativo e inovador, principalmente com o advento das Tecnologias da informação e comunicação, onde a velocidade e a mediação da informação ultrapassaram barreiras de tempo e espaço. Bibliotecários precisam sair da visão tradicional de biblioteca, de apenas guardião do acervo, para serem mediadores da informação, que atuem com dinamicidade e criatividade, seja no espaço físico, digital ou virtual.

A sociedade atual, a chamada Sociedade da Informação não só necessita, como exige profissionais da informação, que conheçam seus usuários, suas necessidades e Revista Brasileira de Biblioteconomia e Documentação - v. 13, n. esp. CBBD 2017 


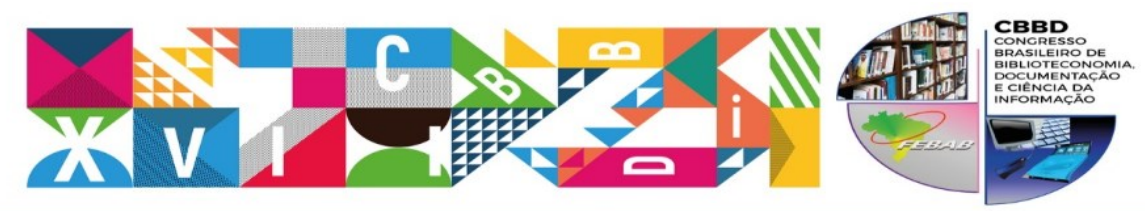

XXVII CONGRESSO BRASILEIRO DE BIBLIOTECONOMIA, DOCUMENTAÇÃO E CIÊNCIA DA INFORMAÇĀO

TEMA cENTrRL: Objetivos para o Desenvolvimento Sustentável das Naçōes Unidas:
como as bibliotecas podem contribuir com a implementaçăo da Agenda 2030

demandas informacionais. Para que assim, possam formar usuários críticos, tendo também como meta fundamental proporcionar a autonomia desses.

Na biblioteca escolar o papel do bibliotecário é essencial para o desenvolvimento de práticas mediacionais, que venham a contribuir para as práticas pedagógicas e construção do conhecimento. Nessa concepção o estudo parte da seguinte indagação: quais as práticas de mediação da informação realizadas na biblioteca Madre Paula do Colégio Santa Teresa de Jesus?

Desta forma a pesquisa tem como objetivo geral: investigar as atividades de mediação da informação implícita e explícita realizadas na biblioteca Madre Paula do Colégio Santa Teresa de Jesus. E objetivos específicos: Identificar práticas mediacionais no âmbito da mediação implícita e explícita; descrever a realidade mediacional da biblioteca Madre Paula.

A pesquisa buscará colher dados com a bibliotecária sobre as práticas mediacionais realizadas na biblioteca do Colégio Santa Teresa de Jesus, e buscou avaliar as opiniões dos usuários (alunos e professores) sobre essas práticas. Acredita-se que o estudo é relevante, na medida em que, a partir desses resultados, será feito uma análise do que pode ser ampliado e melhorado na Biblioteca Madre Paula, para aperfeiçoar a realização das práticas mediacionais desse ambiente, em prol da construção do conhecimento.

\section{MEDIAÇÃO DA INFORMAÇÃO}

Almeida Junior (2009) classifica a mediação da Informação em implícita e explícita, sendo a primeira a seleção dos materiais que compõem o acervo da biblioteca, todo o processo técnico, organização, sinalização, aquisição etc. E mediação explícita acontece nos serviços de informação e referência. Atividades em que o bibliotecário tem contato direto com o usuário, ações culturais, palestras, minicursos etc.

O usuário é foco da mediação, pois é a partir dele que a mediação se concretiza com a apropriação da informação. 0 autor salienta que mediação é: 


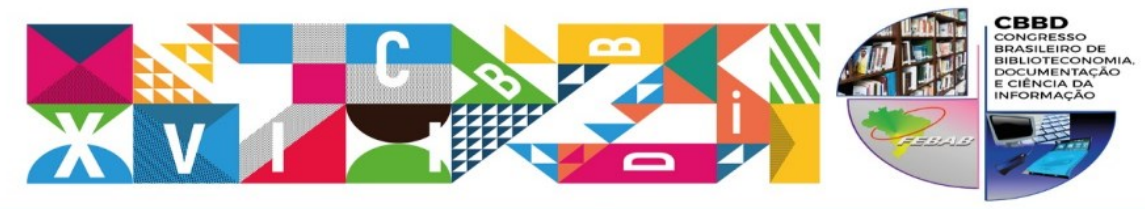

XXVII CONGRESSO BRASILEIRO DE BIBLIOTECONOMIA,

DOCUMENTAÇÃO E CIÊNCIA DA INFORMAÇĀO

TEMA CENrRal: Objetivos para o Desenvolvimento Sustentável das Naçōes Unidas:
como as bibliotecas podem contribuir com a implementaçăo da Agenda 2030

Toda ação de interferência realizada pelo profissional da informação, direta ou indiretamente; consciente ou inconsciente; singular ou plural, individual ou coletiva, que propicia a apropriação da informação que satisfaça, plena ou parcialmente, uma necessidade informacional (ALMEIDA JUNIOR, 2009, p.3).

Compreende-se que a mediação é ação constante no ambiente informacional. Sendo seu objetivo primordial, a apropriação da informação. Na medida em que a mediação pressupõe transformação, produção de sentido e construção do conhecimento. Freire (2006, p.47) colabora afirmando que "ensinar não é transferir conhecimento, mas criar possibilidades para a sua própria produção ou a sua construção". Ou seja, o profissional deve elaborar estratégias que dê subsídios para que os usuários possam ter a capacidade e possibilidade de apropriar-se e construir conhecimento.

Para fortalecer esse diálogo pode-se apresentar as ideias de Silva (2010), em que aponta a mediação custodial e a pós-custodial. Onde a primeira, surgiu no século XVIII, caracterizou-se como patrimonialista, historicista, e tecnicista. Voltada para o locus profissional (prática) incluindo arquivos, bibliotecas e museus. Essa mediação era vista como passiva e "negativa", pois tinha como objetivo principal a guarda do patrimônio cultural, e não o acesso, difusão e disseminação da informação. 0 paradigma póscustodial, apresentou mudanças na forma de coletar, organizar, armazenar, recuperar, interpretar e transmitir a informação. Conhecido também como informacional e científico, ao contrário da mediação custodial, visa prioritariamente o acesso à informação.

Quando surgiram as primeiras bibliotecas no Brasil e no mundo, tinham meramente como finalidade a guarda e preservação de documentos, em especial o livro, com acesso muito restrito. Só depois de muitas décadas, esse ambiente foi aberto para a comunidade, e está saindo da visão de quatro paredes (caixa), para um espaço dinâmico, de mediação da leitura, mediação cultural etc.

Desta forma Silva (2015) afirma que, embora a mediação esteja conquistando seu espaço na área da Biblioteconomia e Ciência da Informação, ainda precisa de estudos mais Revista Brasileira de Biblioteconomia e Documentação - v. 13, n. esp. CBBD 2017 


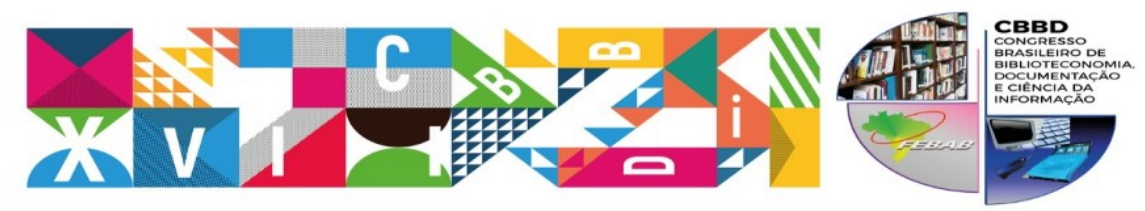

XXVII CONGRESSO BRASILEIRO DE BIBLIOTECONOMIA, DOCUMENTAÇÃO E CIÊNCIA DA INFORMAÇĀO

TEMA CENrRal: Objetivos para o Desenvolvimento Sustentável das Naçōes Unidas:
como as bibliotecas podem contribuir com a implementaçăo da Agenda 2030

sólidos, podendo ser considera "como conjunto construtivo de práticas de intervenção e interferências tipificadas por elementos técnicos, pedagógicos e instituições" (SILVA, 2015, p. 93). A mediação abrange diversas atividades nos centros de informação como: serviços, estudos de usurário, tecnologia, aspectos teóricos-epistemológico, gestão etc.

De acordo com Silva (2015), é fundamental que haja uma compreensão sobre os atributos técnicos, pedagógicos e institucionais da mediação. Esta possibilita novas abordagens e contribui de forma eficiente para pensar a atuação nos centros informacionais. Caracterizando mediação como construto social, crítico e interacionista, Silva (2015) aborda três tipos de mediação:

- Mediação técnica da informação: atividades técnicas da informação, como organização, representação;

- Mediação pedagógica da informação: questões relacionadas ao estudo de usuário, acervo, tecnologias, serviços, avaliação da atuação do centro de informação etc.;

- Mediação institucional da informação: estratégias que o profissional elabora, busca para obter recursos (acervo, aparatos tecnológicos etc.).

É possível perceber que a mediação da informação proporciona novas possibilidades na atuação do profissional da informação. Assim como entende-se a importância da interação entre bibliotecário e usuário. Para que assim, a mediação possa ser realizada com mais precisão, em prol da construção do conhecimento por parte do usuário.

Vale destacar a importância do papel do bibliotecário enquanto mediador da informação. A necessidade desse profissional adquirir habilidades e competências, como, proatividade, criatividade, comunicação etc. para melhor dialogar com seu público. Farias (2014) destaca que o bibliotecário precisa se libertar de ideias conservadoras e estáticas, e atuar com dinamicidade. Fazer da biblioteca um espaço não só de estudo, mas, um ambiente proporciona ações culturais, troca de ideias, eventos literários, aprendizado individual e coletivo. 


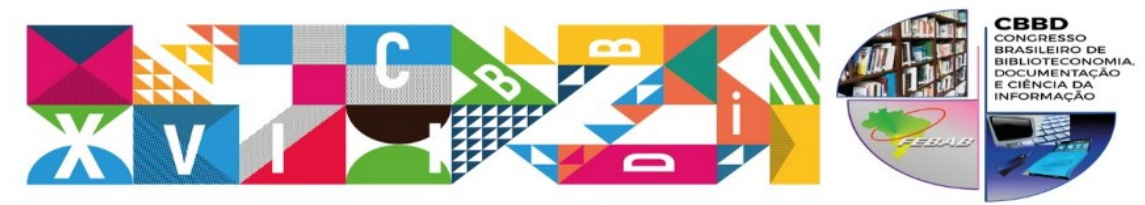

XXVII CONGRESSO BRASILEIRO DE BIBLIOTECONOMIA, DOCUMENTAÇÃO E CIÊNCIA DA INFORMAÇĀO

TEMA cENTrRL: Objetivos para o Desenvolvimento Sustentável das Naçōes Unidas:
como as bibliotecas podem contribuir com a implementaçăo da Agenda 2030

\section{BIBIOTECA ESCOLAR}

A biblioteca escolar, assim como os demais tipos de bibliotecas, precisaram superar diversos desafios, desde que seus objetivos mudaram da preservação para a disseminação e acesso a informação. Hoje a biblioteca escolar pode ser considerada um dos primeiros espaços em que o aluno tem acesso à leitura, ou deveria ter, quando há a existência desse espaço no ambiente escolar.

O Manifesto da Unesco (1976, p.158-163) sobre biblioteca escolar afirma que "Biblioteca é a porta de entrada para o conhecimento, fornece as condições básicas para o aprendizado permanente, autonomia das decisões e para o desenvolvimento cultural dos indivíduos e dos grupos sociais".

Nessa acepção a biblioteca é fundamental no ambiente escolar. A biblioteca escolar quando trabalha em parcerias com os demais profissionais, pode transformar o um simples espaço, em um local dinâmico, de troca de ideias, eventos culturais e de aprendizagem.

Para Cortê e Bandeira (2011, p.6) "a biblioteca é parte integrante do ensinoaprendizagem, que conduz o cidadão a uma formação sólida, garantindo-lhe uma melhor qualidade de vida". 0 objetivo da biblioteca relaciona-se diretamente com o plano pedagógico da escola em que está situada. Sendo ambiente que deve conceder com excelência a mediação da informação explícita e implícita, em especial a mediação da leitura. Bicheri (2008, p.11) corrobora que:

Os mediadores devem agir de forma a tornar o aluno capaz de buscar, selecionar, assimilar a informação de que necessita para seu aprendizado, construir e reconstruir o conhecimento, tornando-se assim livre, autônomo, crítico e também mediador sujeito de sua educação.

Desta forma, compreende-se que o bibliotecário, o professor, e demais profissionais da educação e da informação, devem ter não só o compromisso, como muita responsabilidade no ato de mediação da informação e mediação da leitura. 


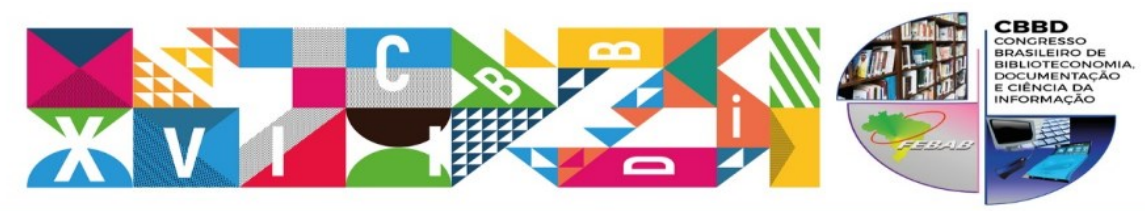

XXVII CONGRESSO BRASILEIRO DE BIBLIOTECONOMIA, DOCUMENTAÇÃO E CIÊNCIA DA INFORMAÇĀO

TEMA cENTrRL: Objetivos para o Desenvolvimento Sustentável das Naçōes Unidas:
como as bibliotecas podem contribuir com a implementaçăo da Agenda 2030

A biblioteca escolar deve ser o centro entre mediação e usuário. Quando há um diálogo direto, a mediação pode acontecer de forma espontânea, possibilitando melhores resultados na apropriação e construção do conhecimento.

De acordo Moro e Estabel (2004, p. 2), “[...] torna-se importante que o professor e o bibliotecário oportunizem o acesso às ferramentas de pesquisa estimulando os usuários a ampliar suas informações, desenvolver a curiosidade e o espírito crítico [...]”. É basilar a parceria entre bibliotecário, não só para o incentivo à pesquisa, mas para a elaboração de projetos, realização de atividades na biblioteca, e incentivar os alunos a frequentar esse ambiente e participar das ações.

\section{METODOLOGIA}

Este trabalho é de cunho bibliográfico. De acordo com Severino (2007, p. 122)

A pesquisa bibliográfica é aquela que se realiza a partir do registro disponível, decorrente de pesquisas anteriores, em documentos impressos, como livros, artigos, teses etc. Utiliza-se de dados ou de categorias teóricas já trabalhados por outros pesquisadores e devidamente registrados. Os textos tornam-se fontes dos temas a serem pesquisados. 0 pesquisador trabalha a partir das contribuições dos autores dos estudos constantes dos textos.

Neste tipo de pesquisa os pesquisados têm contato direto com o material publicado sobre o tema utilizado em sua pesquisa.

Este estudo quanto aos fins, caracteriza-se como descritivo. Para Gil (2008) tem como intuito descrever as características de terminada população, tendo como uma de suas características coletas de dados, questionários e observação sistemática.

A pesquisa é de natureza qualitativa e quantitativa. Para Kauark, Manhãe e Medeiros (2010, p. 26) a pesquisa quantitativa é "o que pode ser quantificável, o que significa traduzir em números, opiniões e informações". Ou seja, foi condensado em números as respostas dos usuários sobre as práticas de mediação da informação explícita 


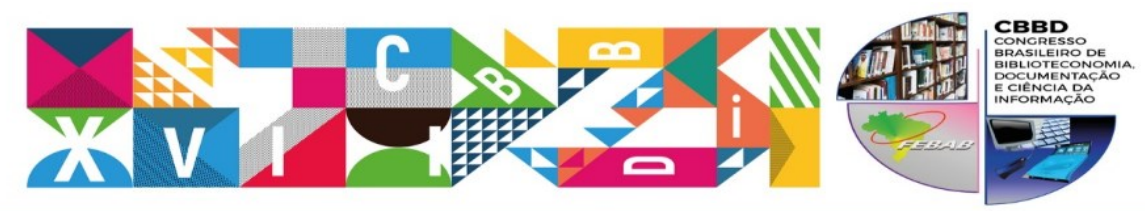

XXVII CONGRESSO BRASILEIRO DE BIBLIOTECONOMIA, DOCUMENTAÇÃO E CIÊNCIA DA INFORMAÇĀO

TEMA CENrRaL: Objetivos para o Desenvolvimento Sustentável das Naçōes Unidas:
como as bibliotecas podem contribuir com a implementaçăo da Agenda 2030

e implícita. E qualitativo porque houve a interpretação das observações descritas pela bibliotecária, e respostas dos usuários também, com atribuição de significados.

Para a coleta de dados foi aplicado questionário. Para Gil (1987, p. 124), essa técnica tendo como objetivo "o conhecimento de opiniões, crenças, sentimentos, interesses, expectativas, situações vivências etc." E observação para Marconi e Lakatos (2003, p.190) "é uma técnica de coleta de dados para conseguir informações e utiliza os sentidos na obtenção de determinados aspectos da realidade. Não consiste apenas em ver e ouvir, mas também em examinar fatos ou fenômenos que se desejam estudar." Tem como vantagem a coleta de dados sobre um conjunto de atitudes comportamentais típicas.

A escola na qual foi aplicado questionário foi o Santa Teresa de Jesus, localizado em Crato - Ce, colégio particular. A escolha desta instituição privada, foi pelo fato de atuar como bibliotecária. Com o intuito de descrever as atividades mediacionais realizadas na biblioteca dessa instituição, e como os usuários estão avaliando. 0 questionário foi aplicado em três dias do mês de novembro. Tendo como os sujeitos da pesquisa a bibliotecária e trinta usuários da biblioteca em questão, dentre eles, 10 professores e 20 alunos.

\section{ANÁLISE DOS RESULTADOS}

Nessa sessão serão expostas as respostas obtidas dos questionários aplicados para bibliotecária e usuários (alunos e professores) da biblioteca em questão.

\subsection{Das observações}

- Inicia-se com as observações da bibliotecária que descreveu as atividades realizadas de mediação explícita e implícita na biblioteca do Colégio Santa Teresa de Jesus.

Quadro 1 - Relato das práticas de mediação implícita

\section{Mediação implícita}




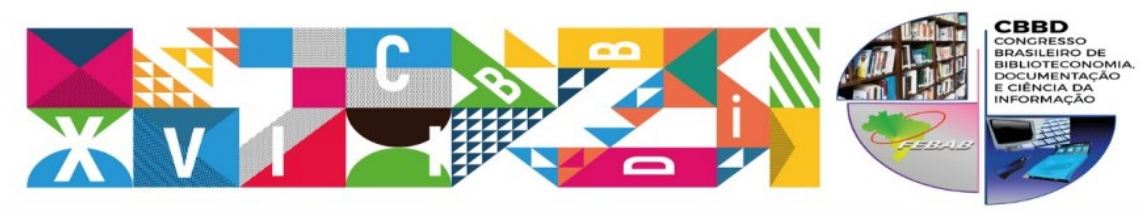

XXVII CONGRESSO BRASILEIRO DE BIBLIOTECONOMIA,

DOCUMENTAÇÃO E CIÊNCIA DA INFORMAÇÃO

TEMA CENTRAL: Objetivos para o Desenvolvimento Sustentável das Naçōes Unidas:
como as bibliotecas podem contribuir com a implementaçăo da Agenda 2030

SELEÇÃO DE MATERIAIS - No início do ano foi colocado na entrada da biblioteca um lista, onde os usuários poderiam sugerir livros. Esses livros estão sendo comprados ao poucos. Vale frisar que a biblioteca tem um acervo bastante antigo, e está passando por atualizações. É importante colocar também até o início de 2016 não tinha bibliotecária.

ORGANIZAÇÃO DO ACERVO - O espaço é dividido por setor, infantil, fundamental e médio (classificado por disciplina e ano). 0 acervo infantil é organizado por cores, em que cada uma amarelo, azul e vermelho representam os anos (série), que podem ler os materiais.

INFRAESTRUTURA - Tem um espaço relativamente grande. É dividido em dois espaços, o infantil e adolescente, porém é espaçoso. 0 espaço e moveis foram pensados por um arquiteto, sem a opinião de um bibliotecário. Tem móveis bonitos, de madeira, mas não são tão resistes ao peso dos livros e as estantes não são adequadas para a altura dos usuários. No geral tem uma infraestrutura consideravelmente boa, porém algumas coisas devem ser alteradas.

SINALIZAÇÃO - a interna está bem sinalizada, os livros estão bem organizados. Os didáticos por disciplina e em cada disciplina por ano (série), tem a placa com a disciplina. Os paradidáticos tem todas as placas sinalizando os gêneros. Porém a sinalização externa precisa existir. A biblioteca precisa de uma identificação na entrada. Assim, como seria interessante placas indicando a direção da biblioteca, visto que o colégio é grande.

Fonte: Elaborado pelos autores.

A seleção de materiais é primordial para compor o espaço da biblioteca, é o maior motivo de indivíduos frequentarem esse espaço. A seleção acontece de acordo com faixa etária. E importante que aconteça também um estudo de usuário, para conhecer as preferências literárias do seu público. A organização é imprescindível para o usuário e o próprio bibliotecário recupere a informação. Em relação a sinalização, é essencial para compor a organização, para recuperação e principalmente para indicar o caminho para chegar até a biblioteca, até o livro almejado, para o acesso a informação.

Quadro 2 - Relato das práticas de mediação explícita

\begin{tabular}{|c|}
\hline Mediação explícita \\
\hline $\begin{array}{l}\text { ATENDIMENTO - é realizado principalmente no intervalo e no final das aulas. A tarde a } \\
\text { biblioteca é aberta para pesquisa, estudo e leituras. }\end{array}$ \\
\hline $\begin{array}{l}\text { Serviços de referência - empréstimo, devolução, reservas entre outros serviços. Foi elaborado } \\
\text { um documento com o título Conhecendo a biblioteca, onde contém todas as normas desse } \\
\text { ambiente, elaboradas e definidas pela bibliotecária. }\end{array}$ \\
\hline $\begin{array}{l}\text { MEDIAÇÃO DA LEITURA - são desenvolvidos vários projetos de incentivo à leitura, Clube do } \\
\text { leitor, (com as turmas do } 6^{\circ} \mathrm{A} \text { e } \mathrm{B} \text { em parceria como professor de português e } 3^{\circ} \mathrm{A} \text { e } \mathrm{B} \text {, } \\
\text { desenvolvido e realizado pela bibliotecária), Hora da leitura, projeto que acontece duas meses } \\
\text { por mês, com os alunos do infantil. O colégio tem um projeto que acontece em parceria com a } \\
\text { biblioteca, onde o professor leva em torno de } 3 \text { vezes por mês os alunos a biblioteca para o }\end{array}$ \\
\hline
\end{tabular}




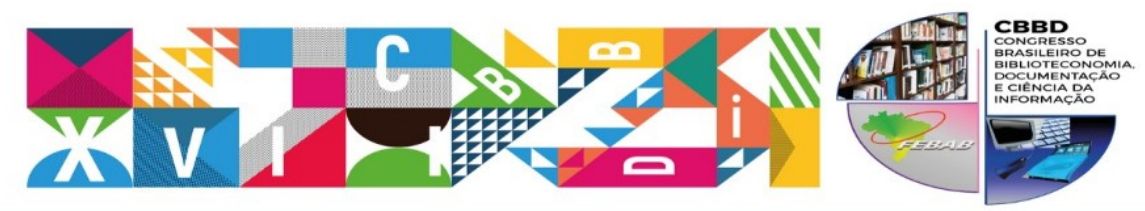

XXVII CONGRESSO BRASILEIRO DE BIBLIOTECONOMIA,

DOCUMENTAÇÃO E CIÊNCIA DA INFORMAÇÃO

TEMA CENrRaA: Objetivos para o Desenvolvimento Sustentável das Naçōes Unidas:
como as bibliotecas podem contribuir com a implementaçăo da Agenda 2030

empréstimo de livros, o objetivo é que eles leiam e façam o resumo. No final do ano tem a premiação dos leitores. A mediação da leitura acontece, por meio de conversas com os usuários, nos intervalos. Sempre há o incentivo à leitura, nos diálogos com os usuários.

INCENTIVO À PESQUISA - o incentivo a pesquisa é bem menos trabalhado do que o incentivo à leitura, acredito ser algo que precisa ser melhorado.

Ação cultural - foi trabalhado, porém centralizou-se muito em dois eventos, folclore e o dia nacional do livro. Pode ser trabalhado melhor, não só em datas específicas, mas todo o ano.

PALESTRAS E EVENTOS - Foram realizadas algumas palestras durante o ano letivo, dentre elas, dia da literatura brasileira, com o tema Patativa do Assaré (para os alunos do ensino médio), fontes de informação (fundamental II e ensino médio), dia do livro infantil (para fundamental II).

INFORMAÇÃO UTILITÁRIA - foi realizado de forma implícita, mas com panfletos e folhetos sobre tema diversos disponibilizados no balcão da biblioteca. Pode e deve ser melhorado. Pode ter informações sobre cursos, saúde, lazer, valores de livros etc.

EDUCAÇÃO DE USUÁRIOS - no início do ano letivo foi realizado com todas as turmas o projeto Conhecendo a Biblioteca. Cada turma ia a biblioteca para uma conversa de 30 minutos, sobre as regras e normas. Passagens rápidas em sala para falar sobre empréstimo e devolução de materiais.

Fonte: Elaborado pelos autores.

Sabe-se que um bom atendimento, um bom serviço de referência, é elemento motivador e de extrema importância para que o usuário sinta-se convidado a voltar ao ambiente informacional. A mediação da leitura segue como o objetivo crucial da biblioteca escolar, em prol da formação do leitor. É importante destacar a importância do incentivo à pesquisa, porém, ainda é muito pouco trabalhado e incentivado em biblioteca escolar, e até mesmo no ambiente escolar. Elemento esse que merece maior atenção. Que pode até mesmo ser trabalhado em palestras, em eventos. Em que esses podem ser realizados, para fomentar a leitura, a pesquisa, a cultura etc. Construir uma biblioteca escolar que atue além dos serviços tradicionais, relacionados apenas ao ambiente escolar, mais disponibilizar informações relacionadas a educação em geral, saúde, cultura, lazer etc. A educação de usuário é necessário em qualquer ambiente de informação, visto que, a biblioteca tem suas normas e regras e devem ser respeitas pelos as pessoas que a frequentam.

\subsection{PERCEPÇÕES DOCENTES E DISCENTES DO COLÉGIO SANTA TERESA DE JESUS SOBRE PRÁTICAS MEDIACIONAIS}

Revista Brasileira de Biblioteconomia e Documentação - v. 13, n. esp. CBBD 2017 

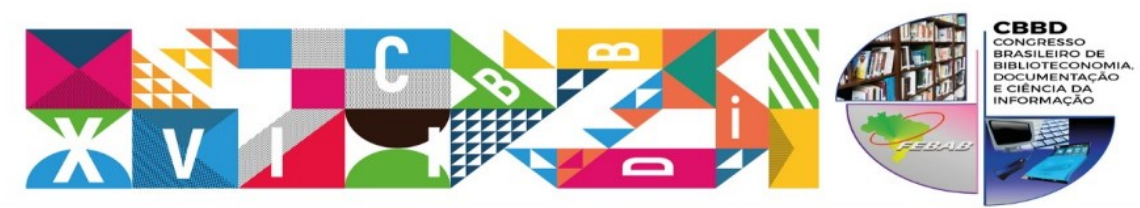

\section{CONGRESSO BRASILEIRO DE BIBLIOTECONOMIA, DOCUMENTAÇÃO E CIÊNCIA DA INFORMAÇÃO \\ TEMA CENraal: Objetivos para o Desenvolvimento Sustentável das Naçōes Unidas:
como as bibliotecas podem contribuir com a implementaçăo da Agenda 2030}

- Respostas dos usuários alunos e professores sobre as práticas mediacionais realizadas na biblioteca.

Quadro 3 - Informações dos usuários

\begin{tabular}{|l|c|c|c|}
\hline \multicolumn{2}{|c|}{ Tipo de usuário } & \multicolumn{2}{c|}{ Sexo } \\
\hline Professor (a) & 10 & 2 - masculino & 8 - feminino \\
\hline Aluno (a) & 20 & 14 - masculino & 6 feminino \\
\hline
\end{tabular}

Fonte: Elaborado pelos autores.

\begin{tabular}{|l|c|c|c|c|c|}
\multicolumn{1}{|c|}{ Quadro 4 - Respostas dos usuários - aluno } \\
\begin{tabular}{|l} 
Práticas de mediação \\
da informação
\end{tabular} & Péssimo & Ruim & Regular & Bom & Excelente \\
\hline Atendimento & & & & 2 & 18 \\
\hline Serviços de referência & & & & 9 & 11 \\
\hline Mediação da leitura & & & 1 & 5 & 14 \\
\hline Incentivo à pesquisa & & & 2 & 6 & 13 \\
\hline Ação cultural & & & 1 & 6 & 13 \\
\hline Palestras e eventos & & & 1 & 4 & 15 \\
\hline Informação utilitária & & & & 2 & 15 \\
\hline Educação de usuários & & & 1 & 2 & 13 \\
\hline Seleção de materiais & & & 1 & 4 & 15 \\
\hline Organização do acervo & & & & 8 & 12 \\
\hline Infraestrutura & & & & 6 & 5 \\
\hline Sinalização & 1 & & & \\
\hline
\end{tabular}

Fonte: Elaborado pelos autores.

A partir do olhar dos usuários (alunos), pode-se perceber que a maioria das atividades de mediação da informação são satisfatórias. Embora, precisem melhorar, para que possam atingir um nível geral de satisfação. É preciso observar que atividades como 

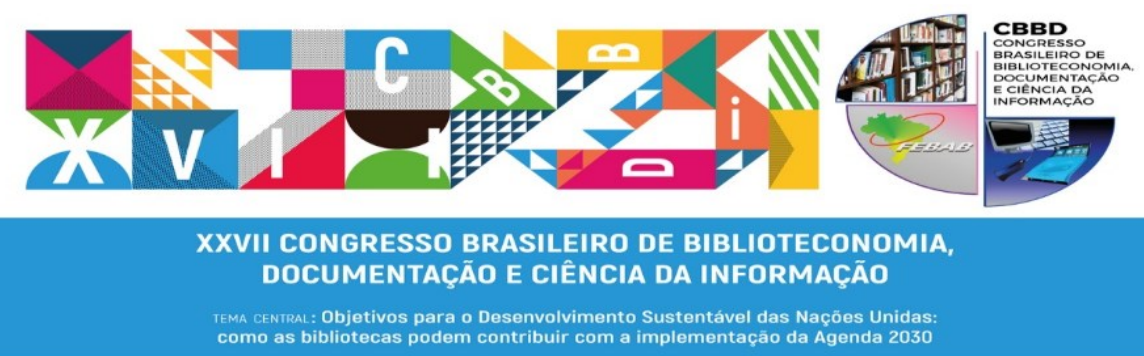

sinalização e serviço de referência precisam ter um olhar mais crítico a esse respeito, em especial a sinalização. É importante ressaltar que esta relaciona-se não só a sinalização interna, mas também com a externa.

Quadro 5 - Respostas dos usuários - professor

\begin{tabular}{|l|l|l|l|l|l|}
\hline $\begin{array}{l}\text { Práticas de mediação da } \\
\text { informação }\end{array}$ & Péssimo & Ruim & Regular & Bom & Excelente \\
\hline Atendimento & & & & 3 & 7 \\
\hline Serviços de referência & & & & 6 & 4 \\
\hline Mediação da leitura & & & 1 & 2 & 7 \\
\hline Incentivo à pesquisa & & & 1 & 4 & 5 \\
\hline Ação cultural & & & & 4 & 6 \\
\hline Palestras e eventos & & & 2 & 6 & 4 \\
\hline Informação utilitária & & & 1 & 3 & 5 \\
\hline Educação de usuários & & & & 2 & 7 \\
\hline Seleção de materiais & & & 2 & 3 & 7 \\
\hline Organização do acervo & & 1 & 3 & 1 & 7 \\
\hline Infraestrutra & & & 2 & 8 \\
\hline Sinalização & & & & 3 \\
\hline
\end{tabular}

Fonte: Elaborado pelos autores.

Todas as atividades descritas estão, na visão dos usuários (professores), como boas ou excelente. Pode-se observar que esta categoria de usuários tiveram um olhar mais criterioso na avaliação das práticas mediacionais. É bastante importante fazer uma comparação entre as respostas dos tipos de usuários. Talvez, por questão de tempo, os alunos frequentem mais a biblioteca do que os professores, e tenha uma maior visão das ações realizadas nesse ambiente. Em contraponto, o professor já avalia de forma mais criteriosa, por ter tido experiências com outros tipos de bibliotecas, e por ter um olhar mais crítico.

Nas duas categorias de usuários o item sinalização não está tão satisfatório. Visto que no questionário refere-se sobre a sinalização no contexto geral, sem especificar em Revista Brasileira de Biblioteconomia e Documentação - v. 13, n. esp. CBBD 2017 


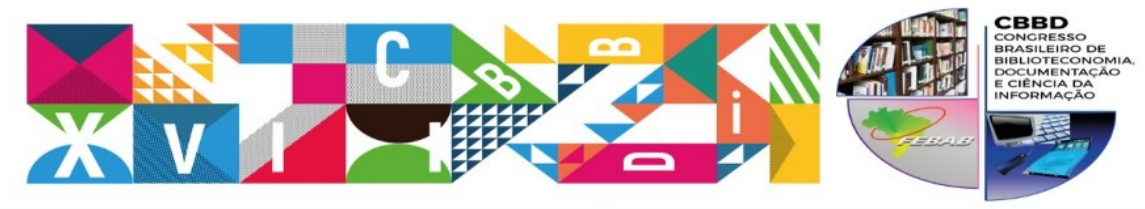

XXVII CONGRESSO BRASILEIRO DE BIBLIOTECONOMIA,

DOCUMENTAÇÃO E CIÊNCIA DA INFORMAÇÃO

TEMA CENTRAL: Objetivos para o Desenvolvimento Sustentável das Naçōes Unidas:
como as bibliotecas podem contribuir com a implementaçăo da Agenda 2030

interna e externa. Vale colocar que sinalização é categoria de extrema importância, tanto a externa, quanto a interna. A primeira como forma de direcionar o usuário que não conhece ainda a biblioteca. E a interna para guia-los ao material desejado. No geral percebe-se que acontecem muitas práticas mediacionais na biblioteca Madre Paula. E estão satisfazendo seus usuários. Algumas precisam de um pouco mais de precaução, e que acontecer com mais frequência também.

\section{CONSIDERAÇÕES FINAIS}

Embora a mediação, de acordo com alguns teóricos da Biblioteconomia e Ciência da Informação, esteja em pleno desenvolvimento. É notável sua presença em todas as práticas realizadas na biblioteca. É essencial que os usuários tenham um espaço dinâmico, que propicie a apropriação da informação.

Os usuários, em especial os da biblioteca escolar, almejam por um espaço ativo, onde aconteça atividades culturais e de leitura, além dos requisitos básicos para qualquer ambiente informacional, tais quais atividades de mediação da informação implícita, organização, sinalização, seleção de bons materiais etc. Ser um bibliotecário mediador da informação requer uma postura inovadora e, nesse contexto, busca-se ações que visem atender às necessidades exigidas e denotem o compromisso com a profissão.

As práticas de mediação da informação podem ser melhoradas, por meio de uma maior interação entre bibliotecário, professores, coordenadores e direção. Juntos podem elaborar diversas estratégias de mediação, de forma que possa proporcionar benefícios não só para biblioteca, mas para o índice de educação como um todo. 0 apoio da direção, tanto em relação a questões financeiras, como pedagógicas, é imprescindível, para a efetivação das práticas mediacionais. Essas ações quando pensadas e executadas de forma coletiva, podem proporcionar inúmeros benefícios para a comunidade escolar, além do reconhecimento e valorização do espaço da biblioteca.

Foi possível constatar o impacto positivo das atividades de mediação da informação na biblioteca em questão. Em que são desenvolvidos vários projetos de 


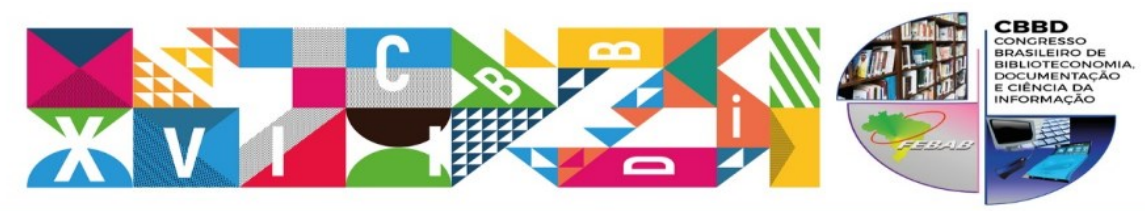

XXVII CONGRESSO BRASILEIRO DE BIBLIOTECONOMIA, DOCUMENTAÇÃO E CIÊNCIA DA INFORMAÇĀO

TEMA CENrRal: Objetivos para o Desenvolvimento Sustentável das Naçōes Unidas:
como as bibliotecas podem contribuir com a implementaçăo da Agenda 2030

incentivo à leitura. E perceber a satisfação dos usuários com os serviços oferecidos. Embora, vale destacar que a biblioteca pode atuar bem mais, e realizar usufruir mais da mediação da informação, com serviços de disseminação seletiva, atividades com o uso das tecnologias. Utilizar essas ferramentas tecnológicas, como aliada, como mais um instrumento que permite colaborar com a mediação da informação.

Todas as mediações descritas demonstram o universo que a biblioteca escolar pode ser e os serviços que pode oferecer para sua comunidade. Espaço que quando conta com atuação de um profissional capacitado e habilitado para estar ali, vai bem além da preservação de materiais, atuando realmente com a mediação e disseminação da informação em prol do aprendizado, construção do conhecimento.

\section{REFERÊNCIAS}

ALMEIDA JÚNIOR, Oswaldo Francisco de. Mediação da informação e múltiplas linguagens.

Revista Tendências da Pesquisa Brasileira em Ciência da Informação, v. 2, n. 1, 2009.

Disponível em: http://inseer.ibict.br/ancib/index.php/tpbci/article/view/17/39 Acesso em: 01 nov. 2016.

BARRETO, Aldo de Albuquerque. Transferência da informação para o conhecimento. In: AQUINO, M. de A. (Org.) 0 campo da ciência da informação: gênese, conexões e especificidades. João Pessoa: Ed. Universitária, 2002. p. 49-57.

BICHERI, A. L. A. D. O. A mediação do bibliotecário na pesquisa escolar face a crescente virtualização da informação. Marília, 2008. 198f. Dissertação (Mestrado em Ciência da Informação) -Universidade Estadual Paulista, 2008. Disponível em:

https://repositorio.unesp.br/handle/11449/93713 Acesso em: 20 dez. 2014.

CÔRTE, Adelaide Ramos e; BANDERIRA, Suelena Pinto. Biblioteca Escolar. Brasília: Briquet de Lemos/Livros, 2011.

FARIAS, M. G. G. Análise da produção, implementação e avaliação de um modelo de mediação da informação no contexto de uma comunidade urbana. 283 f. 2014. Tese (Doutorado em Ciência da Informação) - Universidade Federal da Bahia, Instituto de Ciência da Informação, Salvador, 2014. Disponível em:

http://basessibi.c3sl.ufpr.br/brapci/ repositorio/2015/12/pdf 103c48f3ca 0000017967.pdf Acesso em: 20 out. 2017. 

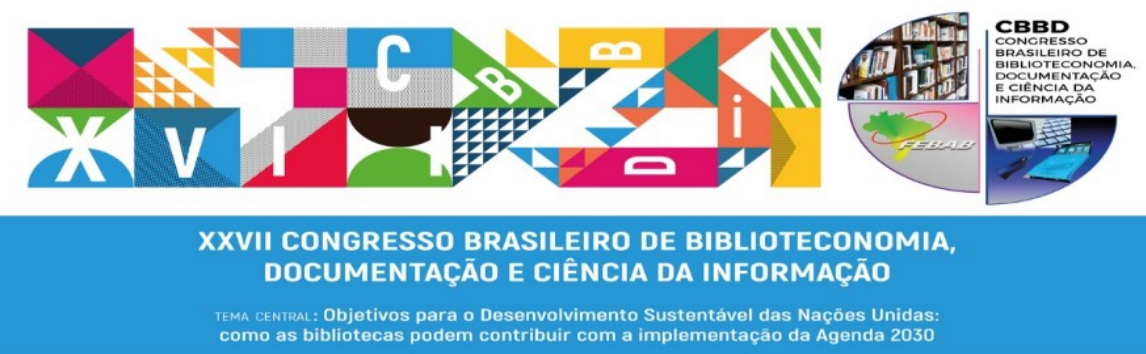

FREIRE, Paulo. Pedagogia da autonomia: saberes necessários à prática educativa. 34 ed. São Paulo: Paz e Terra, 2006.

GIL, Antônio Carlos. Métodos e Técnicas de pesquisa social. São Paulo: Atlas, 1987.

GIL, Antonio Carlos. Como elaborar projetos de pesquisa. 4 ed. São Paulo: Atlas, 2008.

KAUARK, Fabiana da Silva; MANHÃES, Fernanda Castro; MEDEIROS, Carlos Henrique.

Metodologia da pesquisa: um guia prático. Itabuna: Via Litterarum, 2010.

MARCONI, Marina de Andrade; LAKATOS, Eva Maria. Fundamentos de metodologia científica. 5 ed. São Paulo: Atlas, 2004.

MANIFESTO da Unesco sobre bibliotecas públicas. R. Bras. Bibliotecon. e Documentação, São Paulo, v. 7, n. 4/6, p. 158- 163, abr./jun. 1976.

MORO, Eliane Lourdes da Silva; ESTABEL, Lizandra Brasil. A Pesquisa Escolar Propiciando a Integração dos Atores - Alunos, Educadores e Bibliotecários Irradiando o Benefício Coletivo e a Cidadania em um Ambiente de Aprendizagem Mediado por Computador. Novas Tecnologias na Educação, v. 2, n. 1, p. 1-10, mar. 2004.

SEVERINO, Antônio Joaquim. Metodologia do trabalho científico. In: . Teoria prática científica. 23.ed. São Paulo: Cortez, 2007. p. 99-126.

SILVA, Armando Malheiro. Mediações e Mediadores em Ciência da Informação. Prisma.com n. ${ }^{-}$ 9 2010. Disponível em https://repositorioaberto.up.pt/bitstream/10216/26174/2/000106387.pdf Acesso em: 01 nov. 2016.

SILVA, Jonathas Luiz Carvalho. Percepções conceituais sobre mediação da informação. InCID: R. Ci. Inf. e Doc., Ribeirão Preto, v. 6, n. 1, p. 93-108, mar./ago. 2015. Disponível em http://www.revistas.usp.br/incid/article/view/89731/96288 Acesso em: 18 mar. 2015. 